Supporting Information

\title{
Qualitative Alterations of Bacterial Metabolome after Exposure to Metal Nanoparticles with Bactericidal Properties: A Comprehensive Workflow Based on ${ }^{1}$ H NMR, UHPLC-HRMS, and Metabolic Databases
}

Theodoros G. Chatzimitakos and Constantine D. Stalikas

Laboratory of Analytical Chemistry, Department of Chemistry, University of Ioannina, 45110 Ioannina, Greece

\section{Contents}

Figure S1. Images of plates for bactericidal properties of the NPs on E. coli (plates 15) and S. aureus strains.

Figure S2. Bactericidal effect of iron, copper and iron-copper NPs on E. coli and $S$. aureus as a function of their concentration, at different exposure times.

Figure S3. Growth curves of: (A) E. coli and (B) S. aureus cell cultures in three consecutive days.

Table S1. Putatively annotated metabolites by the NMR and search tool of ECMDB and HRMS.

Table S2. Identities, retention times, theoretical and experimental molecular ions, MS/MS data and NMR spectral information of the individual metabolites.

Table S3. Relevant metabolic pathways of exposed and non-exposed bacteria and respective $p$ values. 


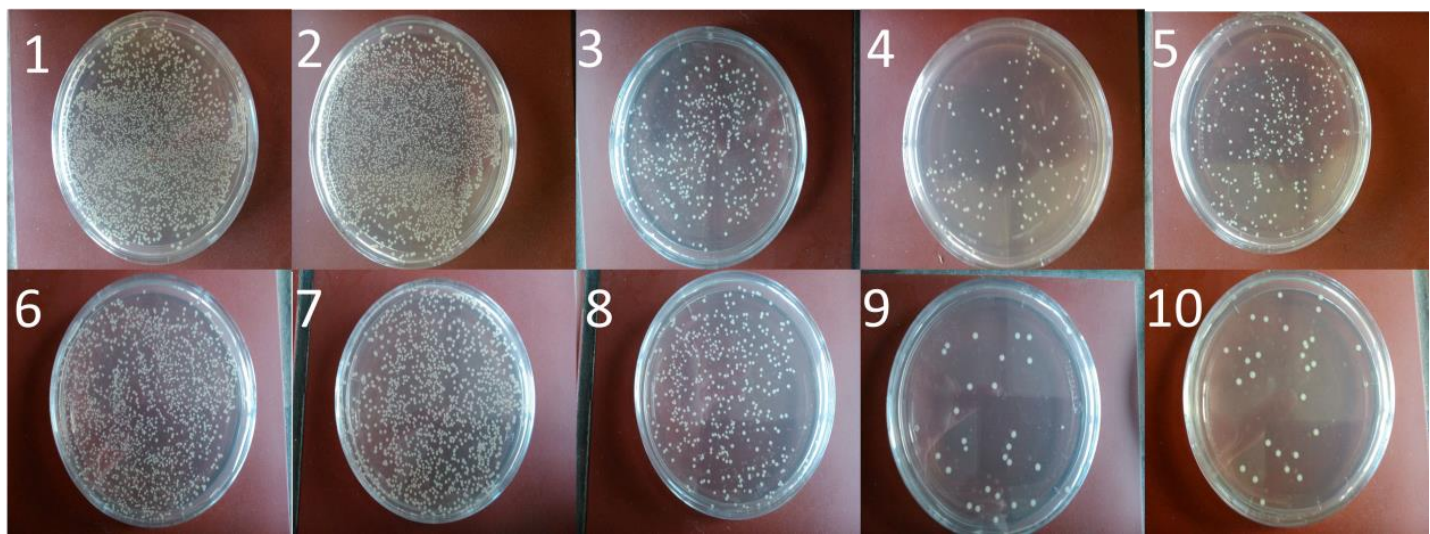

Figure S1. Bactericidal properties of the NPs on E. coli (plates 1-5) and S. aureus strains (plates 6-10). Plates 1 and 6 show untreated bacteria. Plates 2 and 7 show untreated bacteria after $1 \mathrm{~h}$ incubation in saline solution. Plates 3, 4, 5, show E. coli bacteria after treatment with $50 \mu \mathrm{g} / \mathrm{mL}$ of $\mathrm{Fe}, \mathrm{Cu}$ and $\mathrm{Fe}-\mathrm{Cu}$, respectively, for $1 \mathrm{~h}$. Plates 8, 9, 10 show S. aureus after treatment with $100 \mu \mathrm{g} / \mathrm{mL}$ of the same materials, respectively. "Photograph courtesy of 'Theodoros G. Chatzimitakos'. Copyright 2016." 

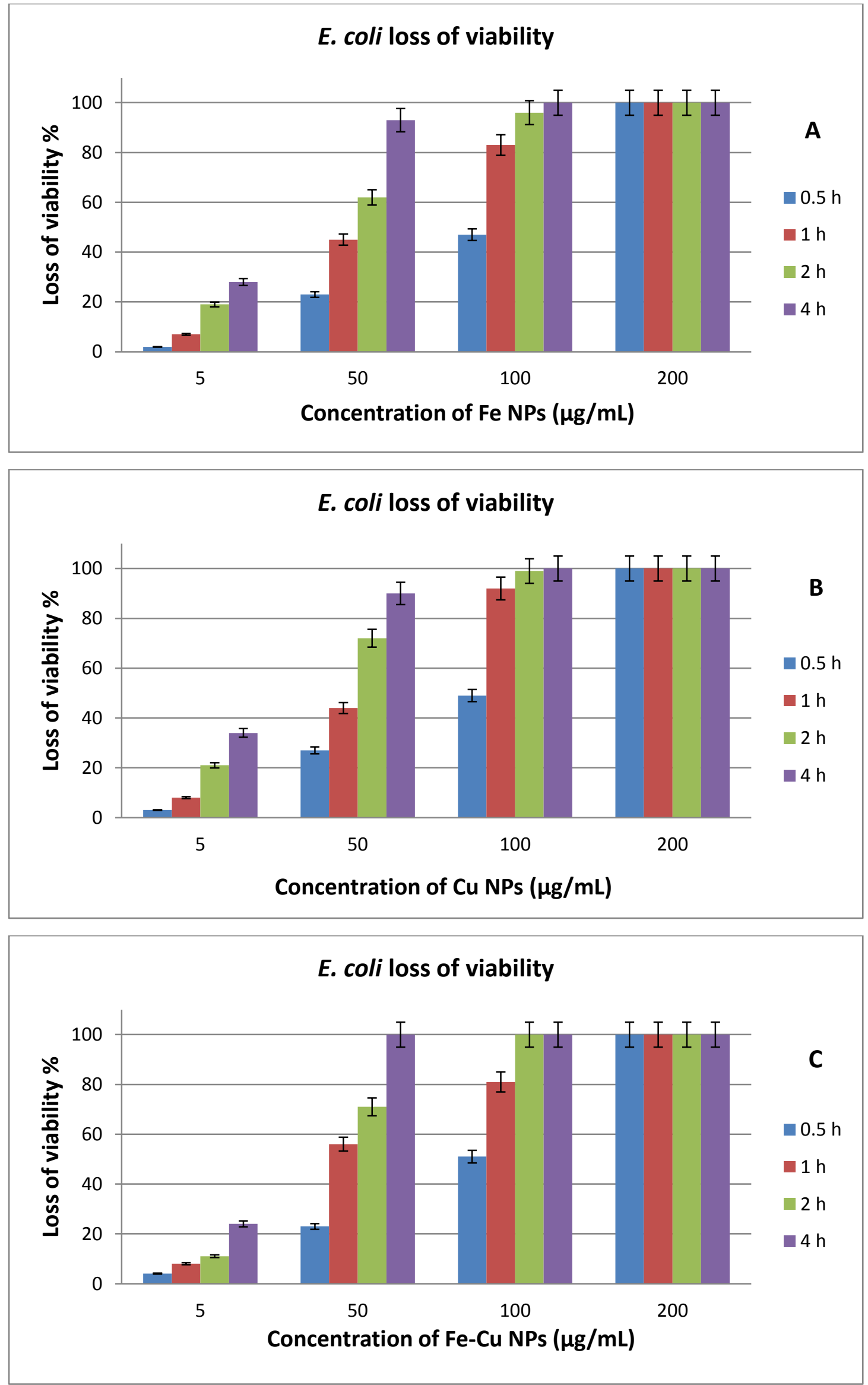

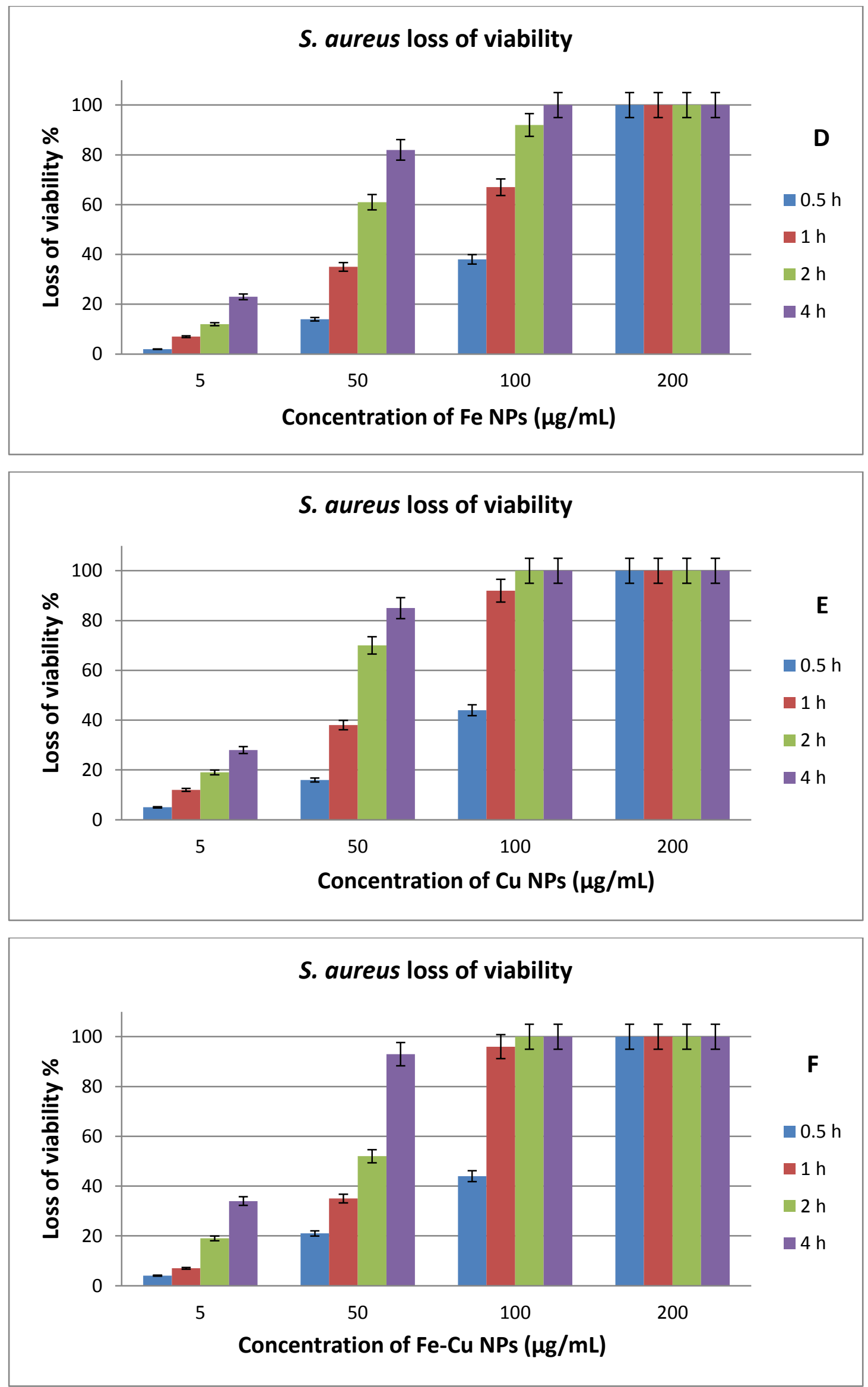
Figure S2. Bactericidal effect of iron, copper and iron-copper NPs on E. coli (A, B and C) and S. aureus (D, E, F) as a function of their concentration, at different exposure times.
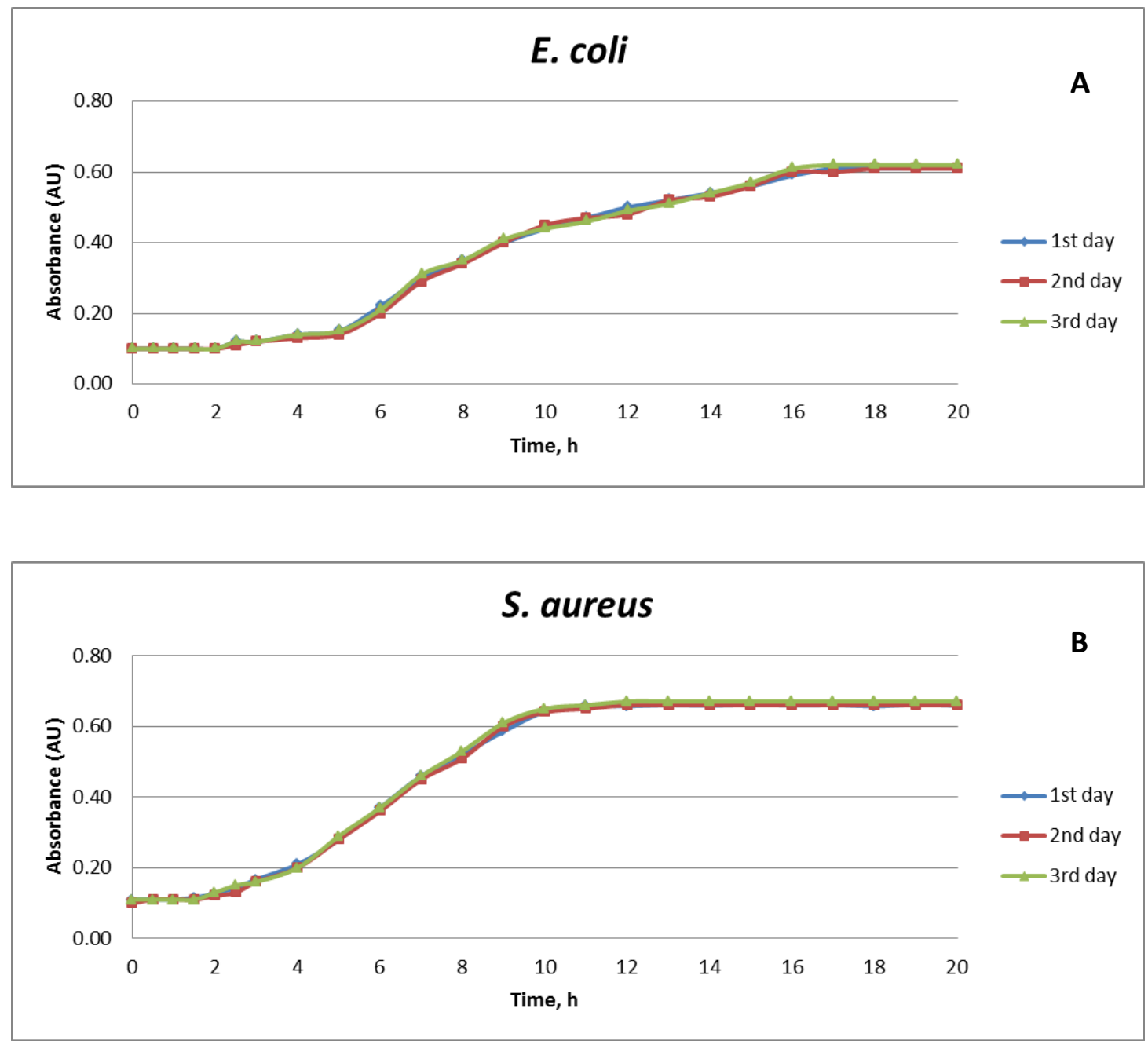

Figure S3. Growth curves of: (A) E. coli and (B) S. aureus cell cultures, in three consecutive days. 